\title{
$>$ Blank Verse: a história e as histórias de William Shakespeare traduzidas em websérie
}

\author{
> Blank Verse: William Shakespeare's stories and history \\ translated to a web series
}

\section{por Manoela Sarubbi Henares Figueiredo}

Universidade Federal da Bahia (UFBA).

E-mail: manoelashf@gmail.com. ORCID: 0000-0003-4500-3152.

\begin{abstract}
Resumo
Blank Verse é uma web série que retrata William Shakespeare e outras figuras históricas do período elisabetano reimaginados como estudantes e professores universitários nos dias atuais. Através de vídeos curtos e postagens em redes sociais, acompanhamos os personagens em suas jornadas como escritores iniciantes num contexto altamente mediado pela tecnologia. A mescla criativa de elementos históricos, biográficos e ficcionais provocaram as reflexões apresentadas neste artigo. A partir do pensamento de teóricos da literatura como Josefina Ludmer e Flora Süssekind; História, como Pierre Nora e Hayden White; e Filosofia, tal qual Roland Barthes e Friedrich Nietzsche, este texto explora o desmantelamento das fronteiras entre verdade e ficção, real e virtual, todos eles produtos da mesma ferramenta: a linguagem.
\end{abstract}

Palavras-chave: William Shakespeare. Literatura. História. Biografia. Ficção.

\begin{abstract}
Blank Verse is a web series that portrays William Shakespeare and other historic characters from the Elizabethan period as university students and staff in the 21st century. Through short episodes we follow their journeys as young writers in an environment that is completely mediated by technology. The creative mix of historical, biographical and fictional elements was the starting point for the reflections presented in this article. Following the theoretical thinking of literary theorists Josefina Ludmer and Flora Süssekind, historians Pierre Nora and Hayden White as well as philosophers Roland Barthes and Friedrich Nietzsche, this text explores the dismantling of the boarders between truth and fiction, real and virtual, all of them the resulting products of the same tool: language.
\end{abstract}

Keywords: William Shakespeare. Literature. History. Biography. Fiction. 


\section{Introdução}

As reflexões apresentadas neste artigo surgem a partir da provocação feita pela web série Blank Verse (2013), obra veiculada através do YouTube, que recria, numa universidade canadense do século XXI, elementos biográficos da vida de William Shakespeare (1564-1616) e de outros autores e personagens históricos contemporâneos do dramaturgo inglês, como Christopher Marlowe, Thomas Kyd, Ben Johnson, o conde de Essex e até mesmo a rainha Elizabeth I, dentre vários outros. Figuras e fatos históricos mesclam-se com elementos ficcionais e personagens das peças e sonetos shakespearianos e, através da livre criação e das escolhas inventivas dos próprios produtores da série, confundem-se num emaranhado de referências intertextuais. Nesse novo contexto, William Shakespeare, ou simplesmente Will, é um ambicioso estudante de escrita criativa que enfrenta as preocupações comuns a um estudante universitário que se muda para uma nova cidade, a fim de investir em sua educação. Enquanto luta para publicar seus textos e sonha com a imortalidade através da sobrevivência de sua obra, ele permite à audiência um vislumbre de seu processo criativo de escrita e reescritura.

O que aqui chamo de provocação da web série é precisamente o que acredito ser um rompimento das fronteiras discursivas que procuram estabelecer uma divisão clara, estanque e autoevidente entre História e ficção. Desenvolvo minhas reflexões a partir de cuidadosa leitura do texto multimídiatico da web série, estabelecendo um cotejo com os textos dramáticos e biográficos que lhe serviram de base e analisando o corpus - no seu caráter extremamente difuso - à luz de uma fundamentação teórica que se desloca entre teorias da literatura, dos estudos da tradução, da mídia audiovisual e, do campo não menos importante, a História. Assim, o argumento que pretendo sustentar é o de que o discurso histórico-científico lança mão de recursos discursivos (muitos deles extralinguísticos) que criam um efeito de transparência e neutralidade da linguagem, fugindo, assim, da instabilidade intrínseca à representação e revestindo-se, portanto, da autoridade da verdade absoluta. Ao mesclar ficção e 
história de maneira tão orgânica e natural, Blank Verse evidencia que a própria História tem também seu caráter ficcional, mais particularmente quando se trata da narrativa biográfica de William Shakespeare, visto que se têm pouquíssimos dados concretos e comprovados sobre sua vida e muito do que se aceita como verdade sobre sua biografia não passa de suposições e conjecturas.

Para os historiadores e demais estudiosos, a escassez de informações sobre William Shakespeare é extremamente frustrante e os obriga a tentar construir uma narrativa coerente a partir dos poucos dados que constam nos documentos que sobreviveram graças a uma reconstrução arqueológica minuciosa, seguindo, assim, uma espécie de trilha de migalhas. Nesse processo, muitas lacunas permanecem em aberto e, segundo Bill Bryson comenta na biografia de sua autoria: "até o mais cuidadoso biógrafo às vezes faz uma suposição - que Shakespeare era católico, que era feliz no casamento, que gostava do campo ou apreciava animais - e em uma ou duas páginas transforma isso em algo como uma certeza" ${ }^{\prime}$. O que desejo propor aqui é pensar essa tendência de estabelecer conexões e atribuir sentidos não como um problema ou uma falha do historiador, mas como um processo natural ao fazer discursivo do qual a História faz parte.

\section{Blank Verse. Web Série como experimentação literária}

Blank Verse é uma web série que transporta personagens do século XVI para a contemporaneidade e os recontextualiza em nossa realidade mediada pela tecnologia e pelas redes sociais. O cenário agora é uma universidade, a Bankside University, e os personagens são todos alunos, professores e funcionários do departamento de escrita criativa. A partir desse produto cultural apresentado num gênero relativamente novo - a web série - procuro refletir sobre a novidade do formato web série e sobre as estratégias de empréstimos, apropriações e ressignificações de outras mídias e gêneros textuais que essa jovem forma vem

\footnotetext{
${ }^{1}$ Bill Bryson. Shakespeare: o mundo é um palco: uma biografia, 2008, p. 23.
} 
utilizando em seu processo de constituir-se como gênero. Para além de uma perspectiva cronológica, a web série parece compartilhar muitas das tendências do que se tem recentemente chamado literatura contemporânea, tais como a exposição e a exploração dos processos de escrita e criação como recursos narrativos; presença massiva do ambiente virtual na vida e na produção artística dos seus personagens; e mesmo a reconfiguração das fronteiras entre realidade e ficção.

Assim como é próprio de novas formas textuais, há, nas web séries, um certo grau de experimentação e hibridismo com outros formatos já consagrados. Ao pensar no romance, gênero preferido pelos autores aspirantes de Blank Verse, e que já reina soberano sobre as demais formas literárias há pelo menos dois séculos, e olhar para o seu momento inaugural, percebe-se que há, na verdade, muito em comum com as tendências literárias mais recentes. No século XVIII, o recém-nascido romance recorria aos diários e cartas, no século XXI, a forma ensaística e os blogs se fazem cada vez mais presentes na literatura. Em ambos os momentos, as narrativas ficcionais fazem uso de gêneros de não ficção para construir seu universo ficcional.

Com esse período inaugural, Blank Verse compartilha a liberdade e a fragilidade de ser uma forma nova: não há ainda parâmetros formalmente estabelecidos e consagrados para comparar, julgar e hierarquizar as séries produzidas para o meio virtual; tampouco há por trás delas prestígio ou força de tradição que lhes garanta o reconhecimento como obra de arte. Assim como os primeiros romances, enquanto lutavam para se estabelecer como tal e criar para si autonomia e mesmo fixar um novo conceito de ficção, as web séries são formas sem forma, em processo. Experimentam, transformam-se, pedem empréstimos a outras artes. Da tradição, mantêm as narrativas seriadas, histórias que são construídas em etapas, ao longo de capítulos ou episódios, estratégia de engajamento de público presente desde os antigos folhetins do século XVIII até 
as atuais e extremamente populares séries de televisão ou mesmo as novelas, no Brasil. $^{2}$

Com o momento contemporâneo do romance, a web série divide a consciência de sua própria instabilidade formal e a potencialização dessa instabilidade como recurso textual. Ao contrário das mídias audiovisuais tradicionais, como o cinema e a televisão, que lançam produtos para consumo em massa, as web séries apostam no "mercado de nichos", caracterizado "pela segmentação dos públicos e pelo valor associado aos bens e serviços com alvos estreitos"3, o que lhes garante, em comparação, uma liberdade criativa muito maior, sem as limitações impostas pela necessidade de conquistar o maior público possível para manter-se rentável e em exibição.

Além disso, as web séries não são simplesmente um novo gênero. Dependem de um aparato tecnológico recente que lhes confere mais possibilidades de inovação. Não se trata apenas de uma mudança de estratégias narrativas, mas de histórias que deixam de ser contadas no papel e migram para um suporte totalmente novo e inacessível (já que inexistente) aos gêneros anteriores. Segundo definição da pesquisadora brasileira Daniela Zanetti:

Uma websérie é uma narrativa audiovisual de qualquer gênero produzida exclusivamente para a Internet, dividida em episódios (os chamados "websódios", websodes em inglês), cada um com tempo de duração variável (em geral, de um a dez minutos), e apresentados com uma certa periodicidade (quase sempre semanal). Webséries podem ser distribuídas diretamente pelos próprios produtores/criadores em sites de disponibilização de vídeos, como You Tube ou Vimeo, e utilizam estratégias narrativas já consolidadas nas séries televisivas, mas incorporando os recursos de "interatividade" dessas plataformas. ${ }^{4}$

Tais produções só podem surgir a partir de um conceito que representa uma mudança no modo de percepção e exploração da internet: a web 2.0, termo popularizado a partir de 2004 e consolidado em 2009 com a publicação do artigo What is Web 2.0 de Tim O'Reilly. ${ }^{5}$ Em linhas gerais, o termo refere-se a uma nova

\footnotetext{
${ }^{2}$ Daniela Zanetti, Web Séries: Narrativas seriadas em ambientes virtuais, 2013, p. 72.

${ }^{3}$ Ibidem, p. 77.

${ }^{4}$ Ibidem, p. 78.

${ }^{5}$ Tim O'Reilley. What is Web 2.0?, 2009.
} 
etapa da era virtual em que a internet deixa de ser um produto e passa a ser uma plataforma. Esta mudança de perspectiva tem várias implicações, sendo uma das mais relevantes a priorização da participação coletiva ao invés da simples publicação de um produto pronto para apreciação passiva. Um exemplo simples que nos permite visualizar essa transformação é o quase completo desaparecimento de enciclopédias tradicionais disponibilizadas virtualmente, como a renomada Britannica Online, e a grande popularização da Wikipédia, um projeto de enciclopédia multilíngue de licença livre, baseado na web e escrito de maneira colaborativa, segundo definição da própria Wikipédia. O uso da palavra projeto é bastante significativo aqui, pois aponta para a valorização do processo infinito de construção e reconstrução do ambiente virtual, em oposição à simples disponibilização de um conteúdo finalizado para apreciação passiva.

O YouTube, hoje a maior plataforma para compartilhamento de vídeos online e a rede através da qual Blank Verse está disponível, é outro exemplo dessa transformação da rede. $O$ próprio YouTube não produz nem disponibiliza conteúdo próprio. Fornece, na verdade, um ambiente de simples navegação para que qualquer usuário seja capaz de compartilhar o conteúdo que preferir. Outro princípio da web 2.0 é o de que usuários agregam valor, por isso sua interface deve ser o mais simples possível para incentivá-los a produzir e compartilhar conteúdo em determinada plataforma.

Zanneti cita a interatividade como um dos pilares do formato web série, mas o conceito de interatividade pode ser mais complexo do que parece. Segundo a crítica literária suíça Marie-Laure Ryan,

Temos a tendência de pensar na interatividade como um fenômeno possibilitado pela tecnologia dos computadores, mas ela é uma dimensão da interação face a face que foi perdida pela comunicação manuscrita e impressa e reintroduzida nas mensagens escritas pelo meio eletrônico, juntamente com várias outras características da comunicação oral. ${ }^{6}$

\footnotetext{
${ }^{6}$ Marie-Laure Ryan, Narrative as Virtual Reality, 2013, p. 204, tradução minha: "We tend to think of interactivity as a phenomenon made possible by computer technology, but it is a dimension of face-to-face interaction that was shut off by manuscript and print writing and reintroduced
} 
Interatividade, portanto, não é uma função ou recurso criado pelo ambiente virtual. É, na verdade, uma característica natural da comunicação humana. Alguns formatos e suportes têm mais ou menos recursos para tentar incorporar às suas narrativas esse aspecto tão caro à comunicação face a face. Poder-se-ia imaginar, e não seria um completo equívoco, que os produtos culturais da era da internet estariam mais propensos a explorar a interatividade com o público. Ryan chama atenção, no entanto, para o fato de que "a Internet, de maneira geral, é um meio interativo, mas muitos dos documentos por ela disponibilizados são textos que seguem um padrão de leitura linear"7. A pesquisadora explora diferentes tipos de interatividade que podem ser divididos em basicamente dois níveis: aquele em que o leitor (ou expectador, internauta, ouvinte etc.) é colocado diante de diferentes opções pré-moldadas e escolhe aquela(s) que desejar, sem, no entanto, modificar de fato o conteúdo daquelas opções. Nesse primeiro nível, a interatividade consiste em organizar elementos de diferentes maneiras, mas sem criar ou adicionar novos elementos. O segundo nível de interatividade é aquele em que o produto final ainda não está definido, como acontece numa conversa face a face, isto é, não há caminhos predeterminados a serem seguidos. Nesse segundo e mais profundo nível de interatividade, a participação do leitor modifica sensivelmente o resultado final da obra apresentada.

O primeiro nível de interatividade, aquele observado em Blank Verse, é possibilitado primordialmente pelos hipertextos. Além de uma narrativa linear central disponibilizada no YouTube, a web série fornece uma série de links que podem ser explorados livremente pelo internauta. "Ao permitir que os leitores determinem seus próprios caminhos de navegação através do conteúdo disponibilizado, os hipertextos promovem o que é comumente considerado um

into written messages by the electronic medium, together with several other features of oral communication.

${ }^{7}$ Ibidem, p. 205, tradução minha: "[...] the Internet as a whole is an interactive medium, but many of the documents it makes available are themselves standard linear texts." 
modo de leitura não linear"8. Assim, o hipertexto funciona como algo extra, fornece dados e informações que não são cruciais à história principal, mas oferecem uma possibilidade a mais que os leitores podem decidir explorar ou não, ou em diferentes níveis de profundidade, a depender do seu desejo e interesse. Os hipertextos "propõem e permitem que os leitores explorem versões alternativas de um núcleo central razoavelmente sólido".

No que o site oficial de Blank Verse chama de extended world - ou mundo expandido, os leitores podem acessar links para os perfis dos personagens no twitter e acompanhar suas interações, ler seus blogs e assistir a vídeos extras com suas performances musicais. Como escritores no começo de suas carreiras, a internet é talvez o único lugar onde têm oportunidade de publicar seus textos e é também o meio pelo qual acompanham as publicações dos colegas. No blog de Will Shakespeare leem-se poemas, textos em prosa e entradas ao estilo de diários. Por vezes tais poemas e tweets são transcritos na tela da web série propriamente dita, sobrepostos às imagens filmadas, conectando as interações face a face com as virtuais e, eventualmente, as segundas interrompem as primeiras, como, por exemplo, numa cena que já é bastante familiar na vida cotidiana: uma mensagem de texto interrompe uma conversa presencial.

Para o expectador-internauta, esse acesso ao universo expandido da web série permite "uma mudança de perspectiva no universo textual. Isso pode significar: abrir uma nova janela, seguir outras linhas do enredo, mudar o foco para um personagem diferente, ouvir uma versão diferente dos fatos ou entrar num novo mundo particular"10. Um episódio de Blank Verse exemplar dessa mudança de perspectiva é o Blankverse Halloween Feature, episódio especial de

\footnotetext{
8 Ibidem, p. 206, tradução minha: "By letting readers determine their own paths of navigation through the database, hypertext promotes what is customarily regarded as a nonlinear mode of reading".

${ }^{9}$ Ibidem, p. 212, tradução minha: "To propose, and let the reader explore, alternative versions of a reasonably solid core of facts".

${ }^{10}$ Ibidem, p. 211, tradução minha: "To shift perspective on the textual world. This can mean: open a new window, follow another plot line, switch focus to a different character, hear a different version of the facts, or enter a new private world".
} 
Halloween, festa de dia das bruxas muito popular no hemisfério norte. Na tela, as imagens monstam a maioria dos personagens numa festa à fantasia, vestidos a caráter, em um bar onde bebem, conversam e declamam poemas. No episódio seguinte, em seu primeiro vlog, Ben Jonson, divide com os expectadores sua frustação por não ter participado da festa, visto que é ainda menor de idade e não tem autorização legal para frequentar bares.

Vê-se então que com as novas possibilidades criadas pela internet, alteram-se não apenas os modos de circulação e o consumo dos produtos audiovisuais, mas surgem também novas estratégias narrativas decorrentes do hibridismo e da convergência de mídias. ${ }^{11}$ Blank Verse mescla técnicas das mídias tradicionais com estratégias próprias do ambiente virtual, oscilando entre o uso da câmera invisível, em terceira pessoa, já consagrada pelo cinema e pela televisão, e o formato vlog (adotado no já mencionado episódio especial de Halloween), no qual o personagem ou YouTuber fala diretamente com a câmera, num "enquadramento frontal, centralizado, que remete ao uso da webcam"12, um tipo de diário filmado mais comum em vídeos não ficcionais e sem aspirações artísticas. Como se a mistura de técnicas novas e tradicionais não fossem suficientes para compor um produto híbrido, Blank Verse ainda recorre a elementos tradicionais do teatro (que sustentam seu eixo temático) para organizar sua narrativa em atos e cenas, e cria, assim, um anacronismo de gêneros que se alinha com o salto temporal que a web série propõe.

A partir da leitura de análises críticas de teóricos da literatura contemporânea, pude perceber que essa instabilidade é também uma característica das produções literárias mais recentes, que parecem apostar cada vez mais na multiplicidade de perspectivas, trazida por "autores que trabalham com 'formas corais' em obras onde se cruzam falas, ruídos e gêneros, conectamse a uma linhagem instabilizadora da literatura brasileira e à produção recente

\footnotetext{
${ }^{11}$ Daniela Zanetti, Op. Cit., p. 71.

12 Ibidem, p. 81.
} 
de cinema, teatro e artes plásticas"13. Ainda que nesse trecho Flora Süssekind esteja se referindo especialmente à literatura brasileira, a autora parece descrever uma forte tendência da produção de arte contemporânea em relação ao "tensionamento propositado de gêneros" e à conexão da literatura a "outras áreas da produção cultural". As web séries, que considero parte dessas "outras áreas da produção cultural ${ }^{14}$, por sua vez, aproximam-se cada vez mais da literatura, adaptando obras literárias para a contemporaneidade virtual.

Esse é o caso de The Lizzie Bennet Diaries (2012-13), web série que reconta o romance Orgulho e Preconceito (1813) de Jane Austen em formato de vlog. A extrema popularidade de The Lizzie Bennet Diaries inaugurou uma tendência de web séries que adaptam obras literárias de domínio público, como Blank Verse, que mescla aos elementos históricos que rodeiam William Shakespeare trechos e elementos narrativos de suas peças, a saber: Os Dois Cavalheiros de Verona (15891592), Titus Andronicus (1588-1593), A Megera Domada (1590-1592), Trabalhos de Amor Perdidos (1595), e Romeu e Julieta (1591-1595), trazendo também, ao longo de toda a sua construção, referências a vários outros trabalhos do dramaturgo, como por exemplo, Ricardo III, Macbeth, Hamlet e até mesmo alguns sonetos. O próprio título da web série, Blank Verse, verso branco, em português, é uma referência clara à estrutura da escrita de William Shakespeare, que era, em geral, metrificada, mas sem rimas - o célebre pentâmetro iâmbico. Isso tudo sem mencionar que os grandes dramaturgos elisabetanos são transportados para a contemporaneidade na condição de romancistas que anseiam por ver seus livros adaptados por Hollywood.

No primeiro ato, o jovem Will Shakespeare escreve seu conto Titus Andronicus e menciona entre suas referências Sêneca, contos folclóricos irlandeses sobre os quais havia feito uma rápida pesquisa no Google, uma conversa de uma colega de sala ouvida por acaso e o cineasta contemporâneo Quentin Tarantino. No mesmo ato, Chris Marlowe vê-se diante do dilema de

\footnotetext{
${ }^{13}$ Flora Süssekind, Objetos verbais não identificados, 2013.

${ }^{14}$ Ibidem.
} 
roteirizar seu romance best-seller Dr. Faustus (título homônimo da peça do dramaturgo Christopher Marlowe, 1587) e enfrenta o julgamento dos colegas por supostamente abrir mão de sua qualidade literária pelo dinheiro dos direitos autorais.

Penso que vale recorrer a um outro conceito da teoria da literatura que merece atenção: o de escrituras ou literaturas pós-autônomas, elaborado por Josefina Ludmer, originalmente com o propósito de pensar as tendências contemporâneas das literaturas sul-americanas, mas que aqui reaproveito e relanço sobre as produções audiovisuais online:

Essas escrituras não admitem leituras literárias; isto quer dizer que não se sabe ou não importa se são ou não são literatura. E tampouco se sabe ou não importa se são realidade ou ficção. Instalam-se localmente em uma realidade cotidiana para "fabricar um presente" e esse é precisamente seu sentido. $^{15}$

A percepção de Ludmer parece-me extremamente valiosa não só para ajudar na compreensão do afrouxamento de fronteiras entre História e ficção, percebido em Blank Verse, mas também para pensar na atuação da tradução e seu papel na construção do hibridismo de gêneros apresentado na web série. Ainda segundo Ludmer,

muitas escrituras do presente atravessam a fronteira da literatura (os parâmetros que definem o que é literatura) e ficam dentro e fora, como em posição diaspórica: fora, mas presas em seu interior, como se estivessem "em êxodo". ${ }^{16}$

A tradução intersemiótica, aquela que opera entre diferentes mídias, frequentemente trabalha exatamente com esse êxodo da literatura para outras artes, nesse caso, têm-se um êxodo um tanto quanto difuso, já que não há um ponto de partida fixo e bem definido. A (re)escritura de Blank Verse não é simplesmente a tradução de uma única peça de William Shakespeare, mas um mosaico de fragmentos de toda a sua obra, além de farta mescla de suas biografias e relatos históricos a seu respeito. $O$ resultado é uma produção audiovisual que

\footnotetext{
${ }^{15}$ Josefina Ludmer, Literatura pós-autônoma, 2007, p. 1.

${ }^{16}$ Ibidem.
} 
transborda intertextualidade. Assim, Blank Verse fica dentro e fora da literatura, não é o que se chamaria tradicionalmente de obra literária, mas mantem com a literatura uma relação tão próxima que torna impossível sua separação.

\section{Ficcionalização do real}

Outro elemento central ao hibridismo de gêneros tão caro à contemporaneidade é o recurso a formas de não ficção. O mesmo ocorreu quando do surgimento do romance, que frequentemente incluía em suas narrativas cartas e diários, e é assim contemporaneamente, quando surgem as web séries que utilizam os vlogs e postagens em redes sociais para compor seu universo ficcional. Em seu momento inaugural, o romance lutava para estabelecer o conceito de ficção, para criar uma separação clara entre a pura e simples mentira e uma narrativa ficcional, na esperança de assim ser reconhecido como um gênero literário digno de prestígio e não uma simples deturpação da verdade. Atualmente, o romance parece esforçar-se para recuperar essa incerteza que o rodeava, na sua condição de forma literária recém-nascida, optando por derrubar cada vez mais as barreiras entre realidade e ficção, que tanto se esforçou para levantar. Recuperando uma das tentativas de nomear essas escrituras contemporâneas já mencionadas, retomo a definição de Josefina Ludmer de literaturas pós-autônomas:

Tomam a forma do testemunho, da autobiografia, da reportagem jornalística, da crônica, do diário intimo, e até da etnografia (muitas vezes com algum "gênero literário" enxertado em seu interior: policial ou ficção científica, por exemplo). Saem da literatura e entram "na realidade" e no cotidiano, (e o cotidiano é a TV e os meios de comunicação, os blogs, o email, internet, etc). Fabricam o presente com a realidade cotidiana e essa é uma das suas políticas. A realidade cotidiana não é a realidade histórica referencial e verossímil do pensamento realista e da sua história política e social (a realidade separada da ficção), mas sim uma realidade produzida e construída pelos meios, pelas tecnologias e pelas ciências. É uma realidade que não quer ser re-presentada porque já é pura representação: um tecido de palavras e imagens de diferentes velocidades, graus e densidades, 
interiores-exteriores a um sujeito que inclui o acontecimento, mas também o virtual, o potencial, o mágico e o fantasmático. ${ }^{17}$

É sob tal perspectiva que desejo debruçar-me sobre a relação nebulosa que Blank Verse estabelece com a realidade na medida em que explora como recurso criativo o caráter ficcional do discurso histórico/biográfico construído em torno de William Shakespeare. Tal relação História x realidade x ficção remete não só ao momento inaugural do romance, no século XVIII, mas também ao momento contemporâneo de produções artísticas dos mais diversos gêneros, quando os limites e, especialmente as zonas de contato entre real e ficcional são deliberadamente forçados e expandidos. Segundo Ludmer, "na 'realidade cotidiana' não se opõe "sujeito' e 'realidade' histórica. E tampouco, 'literatura' e 'História', ficção e realidade'”18.

Blank Verse vê potencial nas lacunas e incertezas biográficas a respeito de William Shakespeare e as explora criativamente: com maior autonomia e muito menos constrições do que o discurso histórico/biográfico, vê-se livre para explorar potencialidades e conexões nas quais os biógrafos hesitariam em mergulhar. Um exemplo significativo é o relacionamento de Shakespeare com o conde de Southampton, Henry Wriothesley (1572 - 1624), a quem dedicou pelo menos dois de seus sonetos. A natureza floreada das dedicatórias foi o suficiente para atiçar rumores dos mais diversos. "Como essas dedicatórias são as únicas duas ocasiões em que Shakespeare fala diretamente ao mundo com sua própria voz, os estudiosos naturalmente se debruçaram sobre elas para ver o que dali poderia ser razoavelmente deduzido"19.

Do fato de que Southampton recusou um contrato de casamento que the traria nobres conexões familiares, depreende-se que poderia estar apaixonado por outra pessoa. Do fato de que foram encontradas pinturas nas quais o conde é retratado com uma aparência um tanto andrógina, imagina-se que essa pessoa poderia ser um homem e, portanto, Shakespeare. Do fato de que as dedicatórias

\footnotetext{
${ }^{17}$ Ibidem, p. 2.

${ }^{18}$ Ibidem, p. 2.

${ }^{19}$ Bill Bryson, Op. Cit., p. 91.
} 
parecem demonstrar familiaridade e talvez até intimidade, deduz-se que os dois poderiam ter um relacionamento amoroso. Biógrafos e historiadores, por mais intrigados que fiquem com a natureza de tal relacionamento, mostram-se receosos em afirmar qualquer coisa com certeza. Blank Verse, por outro lado, não hesita em construir um triângulo amoroso entre Shakespeare, Henry Wriothesley, estudante de doutorando da Bankside University e a assistente administrativa Mary Fitton, recriação de uma dama da corte elisabetana que alguns biógrafos supõem ser a dama escura, a quem muitos outros sonetos shakespearianos são dedicados.

Partindo então da relação difusa entre ficção e realidade, Blank Verse propõe-se fazer o caminho inverso: olhar para a História e pensar também em sua relação com a ficção.

\section{O discurso histórico como representação do passado}

O historiador francês contemporâneo Pierre Nora define a História como a maneira que a nossa sociedade moderna, obcecada com a mudança, encontrou para organizar o passado. ${ }^{20}$ Acredito que sua escolha de palavras seja bastante significativa. Organizar, ele escreve - não relatar, descrever, registrar ou preservar. Organizar implica edição, seleção e escolha, implica atuar sobre algo. Organizar o passado significa docilizá-lo, torná-lo compreensível, palatável. Nora vai adiante e sugere ainda uma distinção entre História e memória:

Memória e história, longe de serem sinônimos, parecem encontrar-se agora numa fundamental oposição. A memória é vida, sustentada por sociedades vivas fundadas em seu nome. Ela permanece em constante evolução, aberta à dialética da recordação e do esquecimento, alheia às suas sucessivas deformações, sujeita à manipulação e à apropriação, suscetível a ser esquecida por longos períodos e eventualmente reavivada. A história, por outro lado, é a reconstrução, sempre problemática e incompleta, daquilo que

${ }^{20}$ Pierre Nora, Between memory and history: les lieux des mémoire, 1989. 
já não é. A memória é um fenômeno permanentemente atual, um laço que nos une ao eterno presente; a história é a representação do passado. ${ }^{21}$

Essa separação entre História e memória pode parecer limitada e, de fato, o próprio Nora trará, mais adiante, uma relativização desses conceitos. Mas, no momento, o que desejo observar aqui é o quanto sua definição de memória permite ampliação, compreendendo variações e transformações, enquanto a História, muito como acontece com a tradução, é apresentada como uma tentativa falha de capturar o passado. É como se, por vestir-se de uma aura de cientificidade, devesse estar imune às deformações, manipulações e apropriações que moldam aquilo que ele chama de memória, mas, sendo uma produção discursiva mediada pela linguagem, obviamente falha nessa missão. Nora afirma ainda que "a memória é por natureza múltipla, mas específica; coletiva e plural, mas individual. A História, em contrapartida, pertence a todos e a ninguém, e daí vem sua reivindicação de autoridade universal"22.

Hayden White, teórico que se tornou referência por sua análise formal das narrativas históricas, desafia essa cientificidade atribuída ao discurso histórico:

Há muito se discute se as explicações dadas pelas ciências naturais e pela história devem ter as mesmas características formais. Esse debate aviva um outro problema: a dúvida se os tipos de leis que podem ser evocados pelas explicações científicas tem ou não sua correspondência no campo das chamadas ciências humanas ou espirituais, como sociologia e história. ${ }^{23}$

\footnotetext{
${ }^{21}$ Pierre Nora, Op. Cit., p. 8, tradução minha: "Memory and history, far from being synonymous, appear now to be in fundamental opposition. Memory is life, borne by living societies founded in its name. It remains in permanent evolution, open to the dialectic of remembering and forgetting, unconscious of its successive deformations, vulnerable to manipulation and appropriation, susceptible to being long dormant and periodically revived. History, on the other hand, is the reconstruction, always problematic and incomplete, of what is no longer. Memory is a perpetually actual phenomenon, a bond tying us to the eternal present; history is a representation of the past".

${ }^{22}$ Ibidem, p. 9, tradução minha: "[...] memory is by nature multiple and yet specific; collective, plural, and yet individual. History, on the other hand, belongs to everyone and to no one, whence its claim to universal authority".

${ }^{23}$ Hayden White, Metahistory: The Historical Imagination in 19th-Century Europe, 2014, p. 12, tradução minha: "There is a long history of dispute over whether natural scientific and historical explanations must have the same formal characteristics. This dispute turns on the problem of whether the kinds of laws that might be invoked in scientific explanations have their counterparts in the realm of the so-called human or spiritual sciences, such as sociology and history".
} 
White explica que as ciências naturais se desenvolvem a partir de acordos entre diversos cientistas e membros das comunidades acadêmicas que determinam qual é a maneira apropriada de lidar com problemas científicos e processar evidências, além de definir o formato no qual uma explicação científica deve ser apresentada. Conclui que "entre os historiadores, nunca existiu tal acordo" ${ }^{24}$. Nos relatos históricos, estrutura e coerência formal são resultado de escolhas discursivas individuais, não havendo acordo comum entre os historiadores que lhes permita seguir uma mesma fórmula.

A percepção de White sobre a História é extremamente inovadora, mas não pelos resultados de sua análise, que são, na verdade, um tanto estruturalistas, mas pelos princípios subjacentes à sua proposta. Mais do que as diversas classificações, categorias e subcategorias que ele determina, é relevante sua atitude diante das narrativas históricas, a percepção de que "parece haver, de fato, um irredutível componente ideológico em todos os relatos históricos da realidade" 25 e, principalmente, sua análise dos textos históricos a partir de categorias e de uma terminologia tradicionalmente reservadas à teoria literária; seu reconhecimento de que a produção de sentidos da História se dá através de estratégias, recursos e estilos narrativos que o autor esquematiza da seguinte forma:

\begin{tabular}{|c|c|c|}
\hline Modo de Enredamento & Modo de Argumento & $\begin{array}{c}\text { Modo de Implicação } \\
\text { Ideológica }\end{array}$ \\
\hline Romântico & Formista & Anarquista \\
\hline Trágico & Mecanicista & Radical \\
\hline
\end{tabular}

\footnotetext{
${ }^{24}$ Ibidem, p. 21, tradução minha: "Among historians no such agreement exists, or ever has existed" Tradução minha".

${ }^{25}$ Ibidem, p. 21, tradução minha: 'There does, in fact, appear to be an irreducible ideological component in every historical account of reality".
} 


\begin{tabular}{|c|c|c|}
\hline Cômico & Organicista & Conservador \\
\hline Irônico & Contextualista & Liberal \\
\hline
\end{tabular}

Quadro 1

Modos Históricos

Fonte: Hayden White, $2014 .^{26}$

Mais do que encaixar os relatos biográficos sobre Shakespeare ou os relatos históricos nos quais o dramaturgo é um personagem em uma das classificações propostas por White, este artigo dedica-se à percepção do autor sobre como o discurso histórico é moldado por decisões e interpretações dos historiadores e biógrafos, cada um criando sua própria verdade ao ordenar os fatos desta ou daquela maneira, para transformar fatos da realidade em narrativas ou explicar os relacionamentos entre eles buscando dar-lhes coerência. A análise de White nos ajuda a perceber que as estratégias utilizadas para construir um relato histórico não são tão diferentes daquelas utilizadas para escrever narrativas ficcionais e torna evidente o fato de que o historiador, longe de ser um cientista que manuseia seu objeto de estudo num ambiente estéril, é um sujeito pelo qual perpassam ideologias e particularidades que certamente moldarão seu produto final.

Em sua Segunda Consideração Intempestiva, Nietzsche argumenta precisamente contra esse fazer histórico que não pertence, que se considera fora da humanidade, como se pairasse sobre ela, em vez de ser por ela produzido. "A história, uma vez que se encontra a serviço da vida, se encontra a serviço de um poder a-histórico, e por isto jamais, nessa hierarquia, poderá e deverá se tornar ciência pura, mais ou menos como o é a matemática"27. Nietzsche aponta que não

\footnotetext{
${ }^{26}$ Ibidem, p. 29, tradução minha: "Mode of Emplotment: Romantic, Tragic, Comic, Ironic. Mode of Argument: Formist, Mechanist, Organicist, Contextualist. Mode of Ideological Implication: Anarchist, Radical, Conservative, Liberal".

${ }^{27}$ Friedrich Nietzsche, Segunda Consideração Intempestiva: da utilidade e desvantagem da história para a vida, 2003, p. 17.
} 
há razão de ser para um pensamento historicista estéril, que se considere alheio e imune ao passado que organiza. Para ele, a História precisa reconhecer que parte sempre de dentro da humanidade, agindo a seu serviço e alterando seus modos de construção discursiva para moldar-se às diferentes demandas que lhe são impostas.

O filósofo alemão afirma, então, que as demandas da humanidade perante a história dividem-se em três aspectos e diante de cada um deles surge um tipo de história que melhor os satisfaz. Diante do desejo de ação e aspiração pelo futuro, apresenta-se a história monumental; diante da busca por preservação e veneração do passado está a história antiquária; diante do sofrimento e anseio por libertação e alívio surge uma espécie crítica de história. ${ }^{28}$

A história monumental, para além de motivar a ação, parece surgir de um desejo pela fama e pelo reconhecimento, pela vontade de deixar para trás um legado: "Mas uma coisa irá viver, o monograma de sua essência mais íntima, uma obra, um feito, uma rara iluminação, uma criação: ela viverá porque a posteridade não pode prescindir dela"29. É a história monumental que move o jovem Will Shakespeare, em Blank Verse, e seu anseio pela sobrevivência, por permanecer imortalizado através de suas obras, por ser lembrado e deixar sua marca nos registros da humanidade. A história monumental é o que lhe possibilita olhar para trás, no seu caso, para Chaucer e Sêneca, e almejar um lugar entre eles nas memórias da posteridade.

Nietzsche chama atenção, no entanto, para o fato de que essa aproximação entre os feitos monumentais do passado e a possibilidade de repeti-los no presente é absolutamente artificial; ela molda, seleciona, edita, altera e apaga tudo que não lhe sirva a esse propósito:

O quanto da diversidade precisa ser desconsiderado aí para que a comparação possa produzir aquele efeito fortalecedor, o quão violentamente a individualidade do passado deve se encaixar em uma

\footnotetext{
${ }^{28}$ Ibidem, p. 18.

${ }^{29}$ Ibidem, p. 20.
} 
forma universal e o quanto todos os seus ângulos e linhas acentuados precisam ser destruídos em favor da concordância! ${ }^{30}$

A narrativa da história monumental está propensa a sofrer apagamentos e no processo de transformar William Shakespeare num destes monumentos também se fizeram atuantes. $O$ primor e a riqueza das peças do dramaturgo inglês são tudo que se tem de concreto a seu respeito. Através de sua obra, é possível conhecê-lo muito bem enquanto autor. Não obstante, os esforços na tentativa de conhecê-lo como pessoa são infinitos e as especulações sobre minúcias de sua vida pessoal são infindáveis. Um número generoso dessas especulações gira em torno de sua sexualidade. Não apenas as dedicatórias já mencionadas, mas também muitas referências nos próprios sonetos de Shakespeare chegaram a levantar dúvidas sobre esse aspecto tão íntimo de sua vida. Infelizmente, além do fato de que algo que deveria ser considerado tão banal gerou (e gera) acaloradas discussões dentro e fora do meio acadêmico, não tardou até que esse possível "desvio" (enfatizo as aspas) da norma heterossexual fosse alvo de apagamentos moralistas e heteronormativos.

A questão da sexualidade de Shakespeare - tanto se ele a exercia como se ela pode ter tido uma orientação inconstante - incomodou seus admiradores [...]. Um dos primeiros editores dos sonetos resolveu 0 problema simplesmente transformando todos os pronomes masculinos em femininos, eliminando assim de um só golpe qualquer vestígio de controvérsia. $^{31}$

Esse simples e tragicômico exemplo mostra como a construção de uma figura histórica está sujeita a recortes e alterações motivadas por fatores tão fúteis quanto os pudores homofóbicos de um editor literário. Uma simples alteração linguística num texto poético é capaz de alterar significativamente a percepção que se tem sobre determinado fato ou traço autoral.

Enquanto a alma da historiografia residir nos grandes estímulos que um homem poderoso retira dela, enquanto o passado precisar ser descrito como digno de imitação, como imitável e como possível uma segunda vez, aquela alma estará em todo caso correndo o risco de se tornar algo distorcido, embelezado e, com isto, próximo da livre invenção poética; sim,

${ }^{30}$ Ibidem, p. 21.

${ }^{31}$ Bill Bryson, Op. Cit., p.144. 
há tempos que não conseguem estabelecer distinção nenhuma entre um passado monumental e uma ficção mítica. ${ }^{32}$

Vê-se novamente que a distinção entre as narrativas ficcionais e os relatos historiográficos torna-se cada vez mais sutil. Novamente, o que se desejar destacar aqui é menos o conteúdo das alterações e/ou edições, e mais o fato de que elas existem e moldam significativamente nossas interpretações.

É também a história monumental, que, certamente, dentre outras atribuições, é responsável pelo estabelecimento dos cânones literários: autores e obras pontuais são selecionados e conectados como numa "cadeia de montanhas [que liga] a espécie humana através dos milênios" ${ }^{\prime 33}$. Ora, uma vez tornadas monumentais, essas obras e autores serão então preservados e venerados, passando então ao domínio da história antiquária, aquela "que olha para trás com fidelidade e amor para o lugar de onde veio e se criou" e estabelece, a partir desse amor por uma origem comum, um sentimento de coletividade e enraizamento numa espécie de "ninho pátrio"34. A história antiquária investiga minunciosamente o passado em busca de relíquias da memória e tem:

[...] uma sede insaciável por novidade, ou, mais corretamente, por antiguidade, e por tudo e por cada coisa; frequentemente el[a] desce tão baixo que acaba por ficar satisfeti[a] com qualquer migalha de alimento e devora com prazer mesmo a poeira de minúcias bibliográficas. ${ }^{35}$

A história antiquária trabalha duplamente sobre a figura de William Shakespeare. Primeiro, porque além de seus sonetos e peças teatrais, a poeira de minúcias bibliográficas é precisamente tudo o que se tem a seu respeito. Não há (ou pelo menos não sobreviveram ou foram encontradas) entrevistas, diários, cartas, nem nada escrito por Shakespeare além de seus textos literários. Ainda assim, é imensurável a quantidade de energia que se investe estudando, esmiuçando, reconstruindo, replicando e visitando os prováveis detalhes de sua

\footnotetext{
${ }^{32}$ Friedrich Nietzsche, Op. Cit., p. 22.

${ }^{33}$ Ibidem, p. 19.

${ }^{34}$ Ibidem, p. 25.

${ }^{35}$ Ibidem, p. 29.
} 
vida pessoal, aquele que pode ter sido seu local de nascimento, o lugar onde possivelmente foi sepultado, as pessoas com quem talvez tenha se relacionado.

Em segundo lugar, a história antiquária atua sobre o dramaturgo inglês, o famoso bardo, porque essa construção discursiva da subjetividade de William Shakespeare como autor parece funcionar mesmo como símbolo da cultura nacional inglesa. Ele se tornou uma espécie de imagem folclórica que atua na narrativa da própria nação, agindo como um dos elementos de unificação de seu povo, contribuindo para a construção do ninho pátrio inglês.

Em seu já clássico texto As culturas nacionais como comunidades imaginadas, Stuart Hall explica que as identidades nacionais tornaram-se fundamentais para a autodefinição do sujeito contemporâneo e que se costuma pensar nelas como "se fossem parte de nossa natureza essencial" ${ }^{36}$, mas, ao contrário de estarem gravadas em nosso material genético, essas identidades são "formadas e transformadas no interior da representação"37, através de símbolos que atuam de forma poderosa na percepção dos sujeitos sobre si mesmos. William Shakespeare é inegavelmente um desses símbolos na cultura inglesa, contribuindo para formar uma imagem nacional que talvez seja percebida ainda mais fortemente por aqueles que a visualizam externamente - é o caso dos leitores e pesquisadores brasileiros - sem aquele conhecimento profundo da diversidade que certamente se faz presente entre o povo inglês, mas que só pode ser obtido através da vivência pessoal.

Desde a imagem de uma verde e agradável terra inglesa, com seu doce e tranquilo interior, com seus chalés de treliças e jardins campestres - "a ilha coroada" 38 de Shakespeare - até às cerimônias públicas, o discurso da "inglesidade" (englishness) representa o que "a Inglaterra" é, dá sentido à identidade de "ser inglês" e fixa a "Inglaterra" como foco de identificação nos corações ingleses (e anglófilos). ${ }^{39}$

\footnotetext{
${ }^{36}$ Stuart Hall, A identidade cultural na pós-modernidade, 2006, p. 47.

${ }^{37}$ Ibidem, p. 48.

${ }^{38}$ Referência a um discurso de exaltação à Inglaterra presente na peça histórica Ricardo II, de William Shakespeare.

${ }^{39}$ Stuart Hall, Op. Cit., p. 52-53.
} 
Um exemplo simples e ao mesmo tempo bastante significativo dessa inventividade nacionalista aparece já nas datas de nascimento e morte de Shakespeare, como explica Bryson:

Não sabemos exatamente quando ele nasceu. Muito engenho se gastou em deduzir de uma ou duas certezas e de algumas tíbias probabilidades a data em que ele veio ao mundo. Por tradição, estabeleceu-se 23 de abril, dia de São Jorge. É o dia nacional da Inglaterra e, por coincidência, a data que Shakespeare morreu 52 anos depois, formando uma certa e irresistível simetria. ${ }^{40}$

Mesmo num exemplo tão pontual, é evidente o esforço que se faz para conectar a narrativa histórica em torno de William Shakespeare à narrativa nacional inglesa, construindo, assim, essa ficção mítica a que Nietzsche se refere. Dessa maneira, a narrativa em questão funciona conectando gerações e enraizando-as ${ }^{41}$ nessa terra-mãe, juntamente com a família real, o chá das cinco e a pontualidade britânica, por exemplo - elementos que poderiam ser mencionados como símbolos da Inglaterra tanto por ingleses quanto por chineses, espanhóis ou brasileiros. A atuação da linguagem é flagrante, portanto, da impossibilidade de transparência e neutralidade do discurso históricocientífico.

Retomando o pensamento cientificista de Nora, fica claro seu reconhecimento de que, quando a histórica lança seu olhar de historicidade crítica sobre si mesma, depara-se com muitos daqueles traços de deformação, transformação e manipulação que gostaria de atribuir à memória:

Toda história é crítica por natureza, e todos os historiadores buscaram denunciar as mitologias hipócritas de seus antecessores. Mas algo extremamente perturbador acontece quando a história começa a escrever a sua própria história. Uma ansiedade historiográfica se manifesta quando a história se propõe a tarefa de detectar em si mesma impulsos externos e se descobre, então, vítima das memórias que havia tentado dominar. ${ }^{42}$

\footnotetext{
${ }^{40}$ Bill Bryson, Op. Cit., p. 30.

${ }^{41}$ Friedrich Nietzsche, Op. Cit., p. 27.

${ }^{42}$ Pierre Nora, Op. Cit., p. 10, tradução minha: "Every history is by nature critical, and all historians have sought to denounce the hypocritical mythologies of their predecessor. But something fundamentally unsettling happens when history begins to write its own history. A historiographical anxiety arises when history assigns itself the task of tracing alien impulses within itself and discovers that it is the victim of memories which it has sought to master".
} 
Essa ansiedade é infinitamente potencializada quando se trata da história nacional: "A sagrada nação agora adquire uma história sagrada; através da nação, nossa memória permanece apoiada em alicerce sagrado"43. Ao olhar para si mesma, a história monumental perceberia que para cada monumento reverenciado, há algo não dito, esquecido. Perceberia, talvez, que ao listar a grandeza poética de William Shakespeare e o chá das cinco como símbolos ingleses, está deixando de mencionar, por exemplo, as crueldades do imperialismo britânico e as cicatrizes por ele deixadas. Para lembrar, é preciso também esquecer. Hall explica que as narrativas nacionais frequentemente precisam ignorar seus "começos violentos" que em geral envolvem um longo processo de conquistas, subjugação e apagamentos: "[...] esses começos violentos que se colocam nas origens das nações modernas têm, primeiro, que ser 'esquecidos', antes que se comece a forjar a lealdade com uma identidade nacional mais unificada, mais homogênea"44. Ou, segundo a leitura que White faz do Nascimento da Tragédia de Nietzsche, esquecer é uma atitude deliberada. ${ }^{45}$

Para Nora, ao olhar para si mesma, a história nacional se auto-mutila com o que Michel Foucault, não duvido, poderia chamar de uma ferida narcísica: "[A história da história] opera principalmente ao apresentar a dúvida, introduzindo um punhal entre a árvore da memória e sua casca de história"46. A imagem de uma árvore de memória - coletiva, instável, vulnerável às manipulações e transformações impostas pelo povo que a produziu - revestida por uma casca de história, imparcial e autoritária, mas superficial - é sem dúvidas uma potente metáfora. O que não me parece produtivo é que a constatação da natureza também fluida e escorregadia do discurso histórico deva instaurar uma ferida, uma vergonha ou representar o reconhecimento de um erro ou uma falha.

\footnotetext{
${ }^{43}$ Ibidem, p. 11, tradução minha: "The holy nation now acquired a holy history; through the nation our memory continued to rest upon a sacred foundation".

${ }^{44}$ Stuart Hall, Op. Cit., p. 60.

${ }^{45}$ Hayden White, Op. Cit., p. 347.

${ }^{46}$ Pierre Nora, Op. Cit., p. 10, tradução minha: "It operates primarily by introducing doubt, by running a knife between the tree of memory and the bark of history".
} 
A organização ou representação do passado de que trata o próprio Nora só pode acontecer através do discurso, da língua, seja ela qual for. E o que ele chama de impulsos externos da construção histórica nada tem de externos. Tais impulsos são perfeitamente adequados, pertencentes ao fazer discursivo que é a História tanto quanto a pesquisa arqueológica ou quaisquer outros procedimentos investigativos. Afinal,

[...] a reconstrução do acontecimento histórico realiza-se, unicamente, por meio da linguagem, que condiciona tal recriação, por um lado, à subjetividade instaurada pelo narrador e, por outro, à movediça natureza do signo linguístico. ${ }^{47}$

Além de ser impossível ao sujeito historiador retirar-se de sua própria escrita, deixando de lado suas crenças, valores e percepções ideológicas, a própria linguagem mostra-se um meio instável e por isso mesmo capaz de criar e moldar a realidade e a história, pois funciona a partir de uma ilusão de transparência e concretude da qual não se pode escapar:

\begin{abstract}
A linguagem não pode ser considerada um simples instrumento, utilitário ou decorativo do pensamento. $\mathrm{O}$ homem não preexiste à linguagem [...]. Jamais atingimos um estado em que o homem estivesse separado da linguagem, que elaboraria então para exprimir o que nele se passasse: é a linguagem que ensina a definição do homem, não o contrário. ${ }^{48}$
\end{abstract}

Não é possível, portanto, separar a linguagem da realidade, uma vez que os discursos criam as verdades. Por que, então, com o fazer histórico seria diferente? O caso da biografia de William Shakespeare é ainda mais emblemático nesse aspecto, pois apresenta mais lacunas a serem preenchidas com interpretação do que dados aceitos como fatos inquestionáveis. Essa consciência da natureza movediça da linguagem, da qual a História faz parte, pode ser capaz de modificar o próprio modo de pensar sobre o discurso histórico-científico. $O$ que antes era visto como incompletude, deformação, ferida ou distorção pode passar a ser percebido como potencialidade. O fato de haver na História um nível de ficção ou invenção poética não precisa ser um problema, mas pode, ao

\footnotetext{
${ }^{47}$ Hernán Yerro, Traduzindo a História: A Guerra das Malvinas na Literatura e na Cinematografia Argentinas, 2012, p. 37.

${ }^{48}$ Roland Barthes, O Rumor da Língua, 2012, p. 15.
} 
contrário, apresentar-se como necessário, fundamental e enriquecedor desse processo de produção discursiva. A edição, seleção e mesmo os esquecimentos são parte intrínseca da construção narrativa dos relatos históricos.

\section{Considerações finais}

O que proponho, então, é um olhar duplamente renovado sobre a História: simultaneamente mais crítico, para que não se caia na ilusão de encontrar ali a verdade, e tolerante, uma vez ciente de que ali não pode estar a verdade, simplesmente porque o que se entende como verdade já vem filtrado pela natureza movediça da linguagem.

Blank Verse, através de sua leitura criativa e sem amarras da História, pode ser vista como agente da história crítica de Nietzsche, aquela que tem os olhos voltados para o presente e para o futuro. É preciso reconhecer o imenso potencial da tradução dupla da História e da ficção de William Shakespeare, uma nova leitura que viaja no tempo e no espaço através de um suporte virtual. São traduções como Blank Verse que paradoxalmente garantem tanto a preservação monumental de William Shakespeare como cânone, quanto o não acabamento da sua história.

A história inacabada (assim como as obras de arte) é uma espécie de obra em perspectiva, aquela que avança, através de sua leitura, para o futuro. A história "acabada" é a história morta, aquela que nada mais diz. História, então, pressupõe leitura. É pela leitura que damos sentido e reanimamos o passado. Nessa medida, a tradução para nós se apresenta como "a forma mais atenta de ler" a história porque é uma forma produtiva de consumo, ao mesmo tempo que relança para o futuro aqueles aspectos da história que realmente foram lidos $e$ incorporados ao presente. [...] O passado não é apenas lembrança, mas sobrevivência como realidade inscrita no presente. ${ }^{49}$

Considerando a visão de Plaza sobre o inacabamento e a sobrevivência instaurados pela tradução, percebo a tradução - aqui exemplificada através da web série Blank Verse - como um dobra na linearidade temporal, uma conexão

49 Julio Plaza, Tradução Intersemiótica, 2003, p. 2, grifos meus. 
paradoxal entre presente, passado e futuro. Paralelamente à visão de Tim O'Reilley sobre a web 2.0, Plaza vê a tradução não como um produto finalizado, mas como uma forma de atuação sobre a realidade. A web série é, portanto, uma obra verdadeiramente contemporânea, à medida que força o leitor a olhar com desconfiança para as fronteiras cada vez mais difusas entre real e virtual, História e ficção.

\section{Referências}

BARTHES, Roland. O Rumor da Língua. Tradução: Mario Laranjeira. São Paulo: WMF Martins Fontes, 2012.

BLANK Verse. Amanda Konkin. Canadá, 2013-2014. Disponível em

https://www.youtube.com/channel/UCUyyMRMl4ZXOu_OtfsgrGaQ Acesso em 8 out 2017.

BRYSON, Bill. Shakespeare: o mundo é um palco: uma biografia. Tradução: José Rubens Siqueira. São Paulo: Companhia das Letras, 2008.

HALL, Stuart. A identidade cultural na pós-modernidade. $11^{\text {a }}$ ed. Rio de Janeiro: DP\&A, 2006.

LUDMER, Josefina. Literatura pós-autônoma. Ciberletras - Revista de crítica literaria y de cultura, n. 17, julho de 2007.

NIETZSCHE, Friedrich. Segunda Consideração Intempestiva: da utilidade e desvantagem da história para a vida. Trad. Marco Antônio Casanova. Rio de Janeiro: Relume Dumará, 2003.

NORA, Pierre. Between memory and history: les lieux des mémoire.

Representations, No. 26, Special Issue: Memory and Conter-Memory. (Spring, 1989), p. 7-24. Disponível em 
http://www.timeandspace.lviv.ua/files/session/Nora_105.pdf. Acesso em 23 de abril de 2017.

O’REILLY, Tim. What is web 2.0? O’Reilly Media. 2009.

PLAZA, Julio. Tradução Intersemiótica. São Paulo, Perspectiva, 2003.

RYAN, Marie-Laure. Narrative as Virtual Reality. Baltimore and London: The John Hopkins University Press, 2013.

SHAKESPEARE, William. Teatro Completo. Tradução Bárbara Heliodora. São Paulo: Nova Aguilar, 2016.

SUSSEKIND, Flora. Objetos verbais não identificados. O Globo. 2013. Disponível em http://blogs.oglobo.globo.com/prosa/post/objetos-verbais-naoidentificados-um-ensaio-de-flora-sussekind-510390.html. Acesso em 8 out 2017.

WHITE, Hayden. Metahistory: The Historical Imagination in 19th-Century Europe. Baltimore: Johns Hopkins University Press, 2014.

YERRO, Jorge Hernán. Traduzindo a História: A Guerra das Malvinas na Literatura e na Cinematografia Argentinas. 2012.132 f. Tese (Doutorado em Letras e Linguística) - Instituto de Letras da UFBA - Universidade Federal da Bahia, Salvador.

ZANETTI, Daniela. Webséries: Narrativas Seriadas em Ambientes Virtuais.

Revista Geminis. Dossiê - TV Pós Digital. São Carlos, Ano 4 - n 1, p. 69-88. 2013.

\section{Referência para citação deste artigo}

FIGUEIREDO, Manoela. Blank Verse: a história e as histórias de William Shakespeare traduzidas em websérie. Revista PHILIA | Filosofia, Literatura \& Arte, Porto Alegre, volume 1, número 2, p. 395 - 421, outubro de 2019. 